\title{
Neurology Health Advocacy Curriculum: Needs Assessment, Curricular Content and Underlying Components
}

\author{
Ahmad Rida Abuzinadah, Lara Cooke
}

\begin{abstract}
Background: Lack of a health advocacy curriculum and clarity are obstacles for effectively teaching neurology health advocacy (NHA) to neurology residents. Our purpose is to assess the need and develop content for a NHA curriculum and to describe its underlying components. Methods: This is a cross-sectional study with two steps. In step one, neurologists and neurology residents at University of Calgary were surveyed about their perception of teaching NHA and asked to rank 56 neurological diseases on a Likert scale based on how well they lend themselves to teaching health advocacy. In step two, curricular items were developed for the top five neurological diseases, using a modified Delphi procedure. The reliability of the survey instrument was determined by Cronbach's alpha. Exploratory factor analysis was used to identify the underlying components of NHA. Results: Forty-six neurologists and 14 neurology residents were surveyed, with a response rate of $88.33 \%$. Fifty-six percent of neurologists and $85 \%$ of residents believe that NHA curriculum is needed. The top five neurological presentations, that lend themselves easily to teaching NHA were: stroke/transient ischemic attacks, alcoholism, epilepsy, Alzheimer's disease, and multiple sclerosis. The survey instrument reliability was 0.97 . Exploratory factor analysis revealed four factors that can explain the variability in the survey instrument: multidisciplinary approach to neurological disorders, prevention of recurrence of neurological disease, collaboration with other medical subspecialties, and communication with professions outside the medical field. Conclusion: Neurologists' and residents' responses support that NHA curriculum is needed. Four components of NHA were identified that can be used for teaching NHA as well as health advocacy in general practice.
\end{abstract}

RÉSUMÉ: Curriculum de promotion de la santé en neurologie : évaluation des besoins, du contenu des programmes d'enseignement et éléments sousjacents. Contexte: L'absence d'un curriculum de promotion de la santé ainsi que le manque de précision sont des obstacles qui entravent l'enseignement efficace de la promotion de la santé en neurologie (PSN) aux résidents en neurologie. Notre but était d'évaluer les besoins et de développer le contenu d'un curriculum portant sur la PSN, ainsi que de décrire les éléments sous-jacents. Méthodologie: Nous avons effectué une étude transversale en deux étapes. Au cours de la première étape, nous avons procédé à une enquête auprès des neurologues et des résidents en neurologie de l'Université de Calgary pour connaître leur perception de l'enseignement de la PSN et nous leur avons demandé de classer, selon une échelle Likert, 56 maladies neurologiques quant à leur aptitude à faire la promotion de la santé. Au cours de la deuxième étape, des items du curriculum ont été développés au moyen d'une méthode Delphi pour les 5 principales maladies neurologiques identifiées. La fiabilité de l'instrument d'enquête a été déterminée au moyen du coefficient alpha de Cronbach. Nous avons procédé à une analyse exploratoire des facteurs pour identifier les éléments sous-jacents de la PSN. Résultats: L'enquête a été effectuée auprès de 46 neurologues et de 14 résidents en neurologie. Le taux de réponse a été de 88,33\%. Cinquante-six pour cent des neurologues et $85 \%$ des résidents croient en la nécessité d'un curriculum de PSN. Les cinq principaux troubles neurologiques qui se prêtent facilement à l'enseignement de la PSN sont : l'accident vasculaire cérébral/ l'ischémie cérébrale transitoire, l'alcoolisme, l'épilepsie, la maladie d'Alzheimer et la sclérose en plaques. La fiabilité de l'instrument d'enquête était de 0,97 . Une analyse exploratoire des facteurs a mis en évidence 4 facteurs qui peuvent expliquer la variabilité de l'instrument d'enquête : une approche multidisciplinaire des maladies neurologiques, la prévention de la récidive de la maladie neurologique, la collaboration avec d'autres sous-spécialités médicales et la communication avec des professionnels hors du champ médical. Conclusion: Les réponses des neurologues et des résidents confirment la nécessité d'un curriculum de PSN. Nous avons identifié quatre éléments de la PSN qui peuvent être utilisés pour l'enseignement de la PSN ainsi que pour la promotion de la santé en pratique générale.

Keywords: Health advocate, curriculum, factor analysis, education, CanMEDS

doi: $10.1017 / \operatorname{cjn} .2016 .405$

Can J Neurol Sci. 2017; 44: 170-176

\section{INTRODUCTION}

In 1996 the Royal College of Physicians and Surgeons of Canada adopted an innovative framework for medical education called the CanMEDS Physician Competency Framework. CanMEDS is composed of seven core competencies; the Framework was intended to support the training of specialist physicians and to enhance patient care. "Health Advocate" is one of the seven roles

From the King Abdulaziz University, Internal medicine department, Neurology division, Jeddah, Saudi Arabia (ARA); Department of Clinical Neuroscience, University of Calgary,

Calgary, Alberta, Canada (LC)

Received May 6, 2016. Final Revisions Submitted August 14, 2016. Date of Acceptance August 19, 2016.

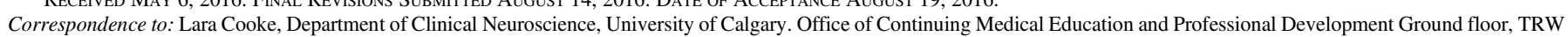
Building, 3280 Hospital Drive NW Calgary, Alberta, T2N 4Z6. Email: lcooke@ucalgary.ca 
identified in the framework. ${ }^{1}$ Health advocacy has been identified as one of the most difficult CanMEDS roles to teach and evaluate. ${ }^{2}$ Many barriers have been identified in the literature and here we will mention three of them. The first barrier is the absence of curricula. ${ }^{3}$ The second barrier is that most physicians and residents are unsure about their role in teaching health advocacy and are reluctant to take on teaching or performing the role. Many felt that it raised expectations beyond their capacity, probably because they think of advocacy as bringing about change in the health related policies and laws, a domain which was found to be the least favorite part of health advocacy for residents to learn. ${ }^{2,4,5}$ This perception does not incorporate the concepts of health advocacy at the individual patient and community level. The third barrier is that it may be a difficult construct to understand. It is argued that it is easier to consider what constitutes health advocacy in practice than to understand its more abstract meanings. ${ }^{6}$

Flynn and Verma conducted a focus group discussion which recommended that the teaching of advocacy should be explicit (i.e. discussed formally rather than just role modeling), and the skills should be developed in a graded fashion, starting from an individual level as the first and easiest step, followed by community level, and finally at the societal level.

We aimed to assess the amount of explicit neurology health advocacy teaching during a neurology residency and to address the three barriers mentioned above through determining the top clinical presentations that neurologists see as most relevant to health advocacy teaching, and relevance to their regular practice. These top neurological presentations were used to develop a detailed curricular content outline through a modified Delphi technique. The Delphi technique is one of the scientific methods used to develop consensus among experts, which allows for a group decision in a variety of scenarios, such as guideline development. This method was chosen as it allows more interaction and feedback within the panel without the constraint of time. ${ }^{7}$ In so doing, we intended to develop curriculum content that would be perceived as relevant, rational, and teachable by our faculty. Asking faculty to teach curriculum content that is directly relevant to their practice would intuitively be expected to foster greater comfort with the teaching of the Health Advocate role. Furthermore, relevance is considered crucial for adult learning (Knowles). Our aim is to assess the need for NHA curriculum, to develop NHA curricular content for the top five clinical presentations that neurologist thought would lend themselves to NHA teaching, and to describe the underlying components of NHA.

\section{METHOD}

The study was carried out in the University of Calgary Division of Neurology. This is a cross-sectional study that includes a survey and modified Delphi procedure in two separate steps.

Our questions are:

1. How often is NHA explicitly taught in neurology programs?

2. What are the clinical diseases in neurology that most easily lend themselves to teaching health advocacy?

3. What specific curricular content items should be included for each of the top five clinical diseases which lend themselves to teaching NHA?

The first two questions were answered through the survey questionnaire that was directed to academic adult neurologists and adult neurology residents and the third question was answered through the Delphi procedure. We included only PGY 2-5 adult neurology residents; PGY-1 residents were excluded because they do not have enough exposure to neurology.

In step one (survey step), the survey questionnaire included three questions to estimate how frequently health advocacy was practiced and taught. The three questions were:

A) Do you think a health advocacy curriculum is needed?

B) How frequently do you practice health advocacy at the patient level?

C) How often do you explicitly teach and/or give feedback to residents on health advocacy?

We developed an initial list of neurological diseases based on prevalence. ${ }^{8,9}$ Next, neurologists and neurology residents were asked to rank these 56 neurological diseases on a Likert scale, based on how strongly each lends itself to teaching Health Advocacy in neurology. This questionnaire was piloted on seven neurologists to ensure that the survey questions were understandable.

In step two, curricular items were developed for the top five neurological diseases identified in the survey, using a modified Delphi procedure.

1. The author created a list of content items for each one of the top five neurological presentations, based on discussion with nurses who work in the particular field, as well as reviewing the resources (local and international organizations' websites and patient educational materials) which are located at each respective subspecialty clinic.

2. Round 1: The list was sent to four experts in each of the five pertinent fields. Ideally two subspecialized expert neurologists and two nurses practicing in each one of these five clinical presentations responded by adding to the list. Based on their responses another, more robust, curricular content list was generated.

3. Round 2: The comprehensive list of curricular content items was sent to the same subgroup to add, eliminate, or combine certain elements. Based on those results, an 'optimal' list was created.

4. Round 3: The 'optimal' list was sent to the same subgroup of subspecialists for validation. Round 3 was repeated until we achieved consensus.

\section{Data analysis}

Data analysis involved the processing of both quantitative and qualitative data. We conducted descriptive statistics, which included the mean, standard deviation, and range of each one of the neurological presentations that was highlighted in the survey. Prioritization of the clinical presentations was based on the mean rating. A Chi square test was conducted to compare the residents' and staff neurologists' perception of the need for the curriculum. The ANOVA test was used to compare residents' and staff neurologists' answers for each one of the neurological disorders that should be included in the curriculum. In addition, a Chi square test was used to compare the residents' frequency of practice and learning of health advocacy versus staff neurologists' frequency of practice and teaching of health advocacy role. A MANOVA test was used to compare responses between staff with different years of practice (1-10 year vs. 11-20 years versus more than 20 years).

Cronbach's alpha was used to test the reliability of the survey. The top five clinical presentations were chosen based on the 
neurologists' responses. In the event that there were more than five clinical presentations with a similar mean rating, the residents' ratings were prioritized, since they were the 'target audience' for the curriculum. Exploratory factor analysis was conducted to measure the construct validity of the survey that was distributed. We used the combined data from neurologists and neurology residents since there was no significant difference in their opinion based on MANOVA testing. Exploratory factor analysis with principal component as the extraction method and the Eigen value was one or more. The rotation method used was Varimax with Kaiser Normalization. For the item to be considered contributing to each factor it has to have loading weight greater than $50 \%$. If the item has a higher loading weight in another factor, it was excluded from the lower loading factor.

\section{RESULTS}

Table 1 shows the demographics of the survey participants, including gender, years of practice, and subspecialty. Thirty-nine neurologists returned the survey out of 46 surveys that were distributed (84.7\% response rate). All 14 of the residents returned the survey ( $100 \%$ response rate). The total combined response rate of neurologists and residents was $88.33 \%$ (53/60).

\section{Perception of teaching health advocacy among neurologists and neurology residents}

Fifty-three percent of neurologists reported that they rarely explicitly teach and/or give feedback to residents on NHA, while $78 \%$ of the residents thought they rarely receive NHA teaching (Table 2). This difference was not found to be statistically significant (Chi square test, $\mathrm{p}=0.159$ ).

Table 1: Demographics of the participants

\begin{tabular}{l|c}
\hline & $\%(\mathbf{n} / \mathbf{N})$ \\
\hline Neurologist: Male & $69.2(27 / 39)$ \\
\hline Residents: Male & $57.1(8 / 14)$ \\
\hline Years of practice as neurologist & $20.5(8 / 39)$ \\
\hline $1-3$ years & $7.7(3 / 39)$ \\
\hline 4-6 years & $15.4(6 / 39)$ \\
\hline $7-9$ years & $28.2(11 / 39)$ \\
\hline $10-20$ years & $28.2(11 / 39)$ \\
\hline$>20$ years & $15.4(6 / 39)$ \\
\hline Subspecialties distribution & $7.7(3 / 39)$ \\
\hline Epilepsy & $17.9(7 / 39)$ \\
\hline Headache & $17.9(7 / 39)$ \\
\hline Stroke & $10.3(4 / 39)$ \\
\hline Multiple Sclerosis & $5.1(2 / 39)$ \\
\hline Neuromuscular & $2.6(1 / 39)$ \\
\hline General Neurology & $7.7(3 / 39)$ \\
\hline Neuroophthalmology & $5.1(2 / 39)$ \\
\hline Movement Disorders & $5.1(2 / 39)$ \\
\hline Dementia &
\end{tabular}

Table 2: How often do you explicitly teach and/or give feedback to residents on health advocacy?

\begin{tabular}{l|c|c}
\hline & Residents \% (n/N) & Neurologists \% (n/N) \\
\hline Never & $7.1(1 / 14)$ & $0(0 / 39)$ \\
\hline Rarely & $78.6(11 / 14)$ & $53.8(21 / 39)$ \\
\hline Regularly & $14.3(2 / 14)$ & $30.8(12 / 39)$ \\
\hline Always & $0(0 / 14)$ & $5.1(2 / 39)$ \\
\hline Unsure & $0(0 / 14)$ & $7.7(3 / 39)$ \\
\hline
\end{tabular}

\section{Perception of the need for NHA curriculum}

Fifty-six percent of neurologists and $85 \%$ of residents reported that they believe that NHA curriculum is needed (Table 3 ). No significant difference was found between the residents' and neurologists' perception of the need for such a curriculum (Chi square test, $\mathrm{p}=0.182$ ).

\section{Clinical disease presentations in neurology that most easily lend themselves to teaching NHA}

On the Likert scale the range of the neurological disease means was 2.7 to 4.7. The top seven disease means were ischemic stroke $(\mathrm{M}=4.7)$, transient ischemic attack ( $M=4.6)$, alcoholism ( $M=4.5)$, epilepsy ( $M=4.4)$, Alzheimer's disease $(M=4.4)$, multiple sclerosis $(\mathrm{M}=4.4)$, and low back pain $(\mathrm{M}=4.4)($ Table-4).

The MANOVA was used to compare the neurologist and resident scores on a Likert scale for each neurological disease; no overall significant differences were found (Wilks' Lambda $\mathrm{F}=3.48, p=0.166)$. A MANOVA was used to compare responses between staff with different years of practice (1-10 years vs. 11-20 years vs. more than 20 years); no overall significant differences were found (Wilks' Lambda $\mathrm{F}=1.515, p=0.378$ ).

\section{Reliability analysis}

Cronbach's Alpha for the survey instrument completed by the neurologists was 0.97 .

\section{Specific curricular content for each of the top five clinical diseases: Delphi procedure}

We used the neurologists' Likert scale means to choose the top five neurological disorders, which were stroke (ischemic), TIA, alcoholism, epilepsy, Alzheimer's disease, and multiple sclerosis (MS). We considered stroke and TIA as one category since they share most of their health needs.

After conducting the five steps mentioned in the methods section, consensus was achieved for all five neurological diseases and the detailed results listing the curricular items are shown

Table 3: Do you think a Health Advocacy curriculum is needed?

\begin{tabular}{l|c|c}
\hline & Residents \% (n/N) & Neurologists $(\%)(\mathbf{n} / \mathbf{N})$ \\
\hline Yes & $85.7(12 / 14)$ & $56.4(22 / 39)$ \\
\hline No & $0(0 / 14)$ & $7.7(3 / 39)$ \\
\hline Unsure & $14.3(2 / 14)$ & $30.8(12 / 39)$ \\
\hline
\end{tabular}


Table 4: Mean Likert scale scores of the top 20 neurological diseases

\begin{tabular}{|c|c|c|c|c|c|}
\hline & Minimum & Maximum & Neurologists means(SD) & Residents means(SD) & Combined means(SD) \\
\hline Stroke (ischemic) & 4 & 5 & $4.7(0.44)$ & $4.9(0.27)$ & $4.8(0.41)$ \\
\hline TIA & 2 & 5 & $4.7(0.62)$ & $4.5(0.65)$ & $4.6(0.63)$ \\
\hline Alcoholism & 2 & 5 & $4.5(0.72)$ & $4.8(0.58)$ & $4.6(0.69)$ \\
\hline Epilepsy & 3 & 5 & $4.5(0.64)$ & $4.9(0.54)$ & $4.6(0.63)$ \\
\hline Alzheimer's disease & 2 & 5 & $4.5(0.72)$ & $4.6(0.50)$ & $4.5(0.67)$ \\
\hline Low back pain & 2 & 5 & $4.4(0.72)$ & $4.2(1.01)$ & $4.3(0.99)$ \\
\hline Multiple sclerosis & 2 & 5 & $4.4(0.782)$ & $4.8(0.43)$ & $4.5(0.73)$ \\
\hline Head injury & 3 & 5 & $4.3(0.73)$ & $4.7(0.47)$ & $4.4(0.70)$ \\
\hline Brain concussion & 3 & 5 & $4.3(0.70)$ & $4.4(0.63)$ & $4.3(0.67)$ \\
\hline Diabetic polyneuropathy & 2 & 5 & $4.3(0.68)$ & $4.5(0.65)$ & $4.3(0.67)$ \\
\hline Parkinson's disease & 2 & 5 & $4.3(0.79)$ & $4.6(0.50)$ & $4.4(0.74)$ \\
\hline Dementia other than AD & 2 & 5 & $4.3(0.85)$ & $4.6(0.50)$ & $4.4(0.79)$ \\
\hline Migraine & 2 & 5 & $4.2(0.70)$ & $4.3(0.83)$ & $4.2(0.72)$ \\
\hline Motor neuron disease & 2 & 5 & $4.2(1.00)$ & $4.9(0.54)$ & $4.4(0.94)$ \\
\hline Degenerative spine diseases & 2 & 5 & $4.1(0.75)$ & $3.9(0.86)$ & $4.0(0.78)$ \\
\hline Muscular dystrophy & 2 & 5 & $4.1(0.93)$ & $4.4(0.75)$ & $4.2(0.89)$ \\
\hline Neuropathic pain & 2 & 5 & $4.1(0.79)$ & $4.4(0.65)$ & $4.2(0.77)$ \\
\hline Intracranial haemorrhages & 2 & 5 & $4.0(0.81)$ & $3.8(0.83)$ & $3.9(0.97)$ \\
\hline Myesthenia Gravis & 2 & 5 & $4.0(0.99)$ & $4.5(0.65)$ & $4.2(0.93)$ \\
\hline Malignant CNS tumors & 1 & 5 & $4.0(1.08)$ & $4.4(0.50)$ & $4.1(0.98)$ \\
\hline
\end{tabular}

in Supplementary Tables 1-5. The curricular items were illustrated with examples and online resources in Supplementary Tables 6-10.

\section{Factor analysis}

Exploratory factor analysis with principal component as the extraction method retrieved four factors that explain $62 \%$ of the variance. These four factors are:

1. Multidisciplinary approach to neurological disorders/ Chronic conditions affecting mobility or cognition.

2. Prevention of recurrence of neurological disease /Paroxysmal transient conditions.

3. Collaboration with other medical subspecialties.

4. Collaboration and communication with professions outside the medical field / Chronic conditions affecting cognition with potential improvement.

Table 5 lists the neurological presentations that load into these factors in descending order.

\section{DISCUSSION}

This study showed that $85.7 \%$ of neurology residents and $56 \%$ of neurologists think that a health advocacy curriculum is needed. This finding is consistent with Wright's work with pediatric residents, which found that $89 \%$ of the participating residents thought that such a curriculum is needed. ${ }^{10}$ Our study is the first one that confirms this finding within the field of neurology.
Most neurology residents $(78.6 \%)$ indicated that they rarely receive teaching on health advocacy. In addition, $53.8 \%$ of neurologists stated that they rarely give residents formal instruction or feedback on health advocacy. This finding has been reported previously in other fields. For example, Leveridge and his colleagues surveyed urology residents in 2007 and found that only $11 \%$ of the respondents felt that health advocacy was frequently addressed by their faculty. Forty-six percent of these residents reported that they did not have a mentor to emulate in health advocacy. ${ }^{11}$

There was agreement between neurologists of different years of experience, as well as between neurologists and neurology residents, on the diseases that should have top priority in forming the basis of a health advocacy curriculum. The high reliability of the survey $($ alpha $=0.97)$ indicates that the survey was clear to the participants, which probably contributed to to the consistent responses.

The critical rationale for determining the agreement between residents and staff neurologists is the issue of relevance, which is essential for buy-in, a core element of adult learning according to Knowles. ${ }^{12,13}$

It is already known that health advocacy is generally perceived to be difficult to teach. ${ }^{2,6,14}$ This may have to do with the challenges of understanding the construct. However, achieving an agreement between teachers and learners about what is relevant to the teaching of health advocacy within their own discipline is anticipated to facilitate both teaching and learning (Knowles). ${ }^{13}$

In the second part of the study the Delphi procedure was used to determine curricular content by identifying the aspects of the top five diseases, which the neurologist would ideally address in 
Table 5: Four components underling neurology health advocacy retrieved from factor analysis

\begin{tabular}{|c|c|c|}
\hline & Loading items & Loading weight \\
\hline \multicolumn{3}{|c|}{ First Factor: Multidisciplinary approach to neurological disorders for Chronic conditions affecting mobility or cognition } \\
\hline 1. & Myasthenia Gravis & 0.854 \\
\hline 2. & Parkinson's disease & 0.82 \\
\hline 3. & Motor neuron disease & 0.815 \\
\hline 4. & Malignant CNS tumors & 0.81 \\
\hline 5. & Multiple sclerosis & 0.802 \\
\hline 6. & Metastatic CNS diseases & 0.798 \\
\hline 7. & Dementia other than Alzheimer's disease & 0.763 \\
\hline 8. & Guillian Barre syndrome/CIDP & 0.755 \\
\hline 9. & Alzheimer's disease & 0.741 \\
\hline 10. & Muscular dystrophy & 0.684 \\
\hline 11. & Viral encephalitis & 0.677 \\
\hline 12. & Movement disorders other than PD, ET, dystonia & 0.671 \\
\hline 13. & Myelopathy (traumatic, neoplastic) & 0.65 \\
\hline 14. & Inflammatory myopathies & 0.624 \\
\hline 15. & Dystonia & 0.623 \\
\hline 16. & Acute transverse myelitis & 0.619 \\
\hline 17. & Benign CNS tumors & 0.602 \\
\hline \multicolumn{3}{|c|}{ Second factor: Prevention of neurological disease / Paroxysmal - transient conditions } \\
\hline 1. & Single Seizure & 0.737 \\
\hline 2. & Transient global amnesia & 0.718 \\
\hline 3. & Essential tremor & 0.718 \\
\hline 4. & Febrile Seizure & 0.717 \\
\hline 5. & Ocular cranial nerve palsies (3rd, 4th, 6th ) & 0.698 \\
\hline 6. & Intracranial HTN & 0.675 \\
\hline 7. & Trigeminal neuralgia & 0.622 \\
\hline 8. & Cluster headache & 0.599 \\
\hline 9. & Transient ischemic attack (TIA) & 0.595 \\
\hline 10. & Bell's palsy & 0.582 \\
\hline 11. & Tension type headache & 0.568 \\
\hline 12. & Degenerative spine diseases & 0.537 \\
\hline 13. & Low back pain & 0.531 \\
\hline \multicolumn{3}{|c|}{ Third factor: Collaboration with other medical subspecialties } \\
\hline 1. & Syrinx & 0.817 \\
\hline 2. & Multiple cranial neuropathy & 0.763 \\
\hline 3. & Hydrocephalus & 0.718 \\
\hline 4. & Congenital neurologic deficit & 0.707 \\
\hline 5. & Narcolepsy / sleep disorders & 0.601 \\
\hline 6. & Subarachnoid hemorrhage & 0.573 \\
\hline 7. & Polyneuropathy & 0.533 \\
\hline 8. & Intracranial haemorrhages & 0.509 \\
\hline 9. & Autonomic neuropathy & 0.504 \\
\hline
\end{tabular}

Fourth factor: Collaboration and communication with professions outside the medical field / Chronic conditions affecting cognition with potential improvement

\begin{tabular}{l|l|r}
\hline 1. & Head injury & 0.818 \\
\hline 2. & Brain concussion & 0.759 \\
\hline 3. & Alcoholism & 0.612 \\
\hline 4. & Migraine & 0.533 \\
\hline 5. & Mild cognitive impairment & 0.507 \\
\hline 6. & Epilepsy & 0.501 \\
\hline
\end{tabular}


practice. This is an important contribution to health advocacy teaching in general and in neurology in particular as it goes beyond the general principles of teaching health advocacy to practical, neurology-specific elements. By developing curricular content based on topic areas agreed upon by subspecialist neurologists, this study attempts to address the key aspects of learning theory relating to relevance and goal-directed learning experiences in relation to teaching health advocacy. By identifying content that neurologists should teach directly to patients because they are known to directly impact outcomes, we address both goal-orientation (to improve patient care) and relevance (in discipline-specific areas). Ideally, by choosing curricular content meeting these criteria, we will optimize not only learner engagement, but patient outcomes. ${ }^{6}$

Health advocacy can be difficult to understand, and therefore to teach. Using neurology-specific content can facilitate neurology trainees' learning. ${ }^{6}$

The exploratory factor analysis revealed four factors that explain $62 \%$ of the variability of the responses to the survey instrument. The distinct groupings of diagnoses from the factor analysis appear to align most closely with the types of additional support that may be needed by patients in each of the groups of conditions. The first factor included a group of chronic conditions affecting mobility or cognition that largely share a natural history of insidious progression, which results in patients' health needs continuously changing. Usually these conditions (e.g motor neuron disease, Alzheimer's disease, muscular dystrophies) need a multidisciplinary approach to care, as patients' needs include, for example, physical therapy, occupational therapy, speech and language therapy, social work intervention, etc. Recognizing and addressing these evolving health needs represents a concrete example of health advocacy in practice. This factor was named "Multidisciplinary approach to neurological disorders for Chronic conditions affecting mobility or cognition."

The second factor includes paroxysmal and transient neurological disorders where patients' health needs are mainly focused to avoid future recurrence so this factor was named "Prevention of recurrence of neurological disease for paroxysmal and transient conditions." This factor highlights the importance of involving the neurology residents in educating the patients about how to prevent further events. For example, the two common conditions that neurologists see under this factor are seizures and TIA. The resident should be taught to how to conduct a discussion to prevent further spells by avoiding seizure triggers (in the case of seizures) or risk factor control such as blood pressure control or smoking cessation (in the case of TIA), for example.

The third factor includes conditions requiring cross-disciplinary specialist care. This factor was named "Collaboration with other medical subspecialties." This factor highlights the importance of involving the neurology residents in communications and referral to other medical specialists. For example, this factor included polyneuropathy, which is commonly caused by diabetes and it is important to involve endocrine specialists in patient care to prevent further progression.

The fourth factor includes conditions that require collaboration and communication with professions outside the medical field (e.g. migraine). This factor highlights the importance of teaching the neurology residents the importance of recognizing this kind of patient needs. It seems likely that these conditions group together because of not only their chronicity, but the potential for socioeconomic impact, and the need for substantial advocacy on the part of attending physicians. This includes learning the importance of offering patients (such as migraine patients or epilepsy patients) a letter to their work place to make some adjustment or, if necessary, time off. This factor was named "Collaboration and communication with professions outside the medical field."

Flynn and Verma (2008) addressed the fundamental components of a curriculum for residents in health advocacy. ${ }^{3}$ One of the attributes they identified was being resourceful and up-to-date, which was defined as "aware of available resources and pair these with the current knowledge of best practices for patients." 3 This attribute is consistent with the first and second factors we found. The other attribute they found was assertiveness, which was defined as "arguing on behalf of others by presenting the facts in a cogent and direct fashion." 3 This attribute is consistent with the third and fourth factor we found.

Several study limitations should be considered in interpreting our findings. One is the small sample size of neurologists and neurology residents. The study was also limited to one center, which affects its generalizability. The curricular items derived from the Delphi are not comprehensive, but intended to build the foundation of a health advocacy curriculum. We did not address curricular items for all common neurological disorders such as migraine, low back pain, motor neuron disease, and the other less common disorders noted in the initial survey. The social determinants of health is another key item in the Health Advocate Role as outlined by the RCPSC that was not addressed in this curriculum because it could be argued that it is a generic item across any discipline, and the focus of this study was specific to neurology.

Future studies should address other neurological diseases that were not addressed in this curriculum. Also, involving other centers in developing such curricula will allow more generalizability representing a wider range of neurologists' opinions. Future research should focus on developing instructional methods, educational strategies, implementation plans, and criteria for evaluating the effectiveness of the curriculum. Development of resources to teach faculty how to use such a curriculum may foster its implementation.

\section{ACKNOWLEDGEMENTS}

Ahmad Ridah Abuzinadah was supported by an educational scholarship from King Abdulaziz University, Neurology division, Jeddah, KSA, and by a CTSA grant from the National Institute of Health (NIH)/NCATS awarded to the University of Kansas Medical Center for Frontiers: The Heartland Institute for Clinical and Translational Research No UL1TR000001 (formerly No UL1RR033179). The content of the paper is solely the responsibility of the authors and does not necessarily represent the official views of the NIH or NCATS.

\section{Disclosures}

Ahmad Ridah Abuzinadah has the following disclosures: King Abdulaziz University School of Medicine, Educational scholarship, Fellowship; National Institute of Health (awarded to the University of Kansas Medical Center for Frontiers: The Heartland Institute for Clinical and Translational Research). Cooke reports no disclosures. 


\section{Statement OF AUTHORShIP}

Ahmad Ridah Abuzinadah: study design, data collection, statistical analysis, data interpretation, and writing the manuscript. Lara Cooke: study supervisor, data interpretation and editing the manuscript.

\section{SUPPLEMENTARY MATERIAL}

To view supplementary material for this article, please visit https://doi.org/10.1017/cjn.2016.405

\section{REFERENCES}

1. Frank J. The CanMEDS 2005 physician competency framework. Better standards. Better physicians. Better care. The Royal College of Physicians and Surgeons of Canada. 2005.

2. Verma S, Flynn L, Seguin R. Faculty's and residents' perceptions of teaching and evaluating the role of health advocate: a study at one Canadian university. Acad Med. 2005;80:103-8.

3. Flynn L, Verma S. Fundamental components of a curriculum for residents in health advocacy. Med Teach. 2008;30:e178-83.

4. Wasay M, Hauth E. Advocacy training in neurology: scope and impact. Nat Clin Pract Neurol. 2008;4:114-5.

5. Chamberlain LJ, Sanders LM, Takayama JI. Child advocacy training: curriculum outcomes and resident satisfaction. Arch Pediatr Adolesc Med. 2005;159:842-7.
6. Dharamsi S, Ho A, Spadafora SM, Woollard R. The physician as health advocate: translating the quest for social responsibility into medical education and practice. Acad Med. 2011;86:1108-13.

7. Murphy MK, Black NA, Lamping DL, McKee CM, Sanderson CF, Askham J, et al. Consensus development methods, and their use in clinical guideline development. Health Technol Assess. 1998;2: $1-88$.

8. Sotirios W. Differential Diagnosis in Neurology and Neurosurgery A Clinician's Pocket Guide. Stuttgart:George Thieme Verlag; 2000.

9. MacDonald BK, Cockerell OC, Sander JW, Shorvon SD. The incidence and lifetime prevalence of neurological disorders in a prospective community-based study in the UK. Brain. 2000;123: 665-76.

10. Wright CJ, Moreno MA, Katcher ML, McIntosh GC, Mundt MP, Corden TE. Development of an advocacy curriculum in a pediatric residency program. Teach Learn Med. 2005;17:142-8.

11. Leveridge M, Beiko D, Wilson JW, Siemens DR. Health advocacy training in urology: a Canadian survey on attitudes and experience in residency. Can Urol Assoc J. 2007;1:363-9.

12. Hartzell JD. Adult learning theory in medical education. Am J Med. 2007;120:e11-3.

13. Kuchinke K. Adult development towards what end? A philosophical analysis of the concept as reflected in the research, theory, and practice of human resources development. Adult Educa Quart. 1999;49:148-62.

14. Earnest MA, Wong SL, Federico SG. Perspective: Physician advocacy: what is it and how do we do it? Acad Med. 2010;85: 63-67. 